\title{
Congenitally corrected transposition of the great arteries
}

\author{
T. K. Susheel Kumar \\ Department of Congenital Cardiothoracic Surgery, NYU Langone Health, New York, NY, USA \\ Correspondence to: T. K. Susheel Kumar, MD. Associate Professor, Department of Congenital Cardiothoracic Surgery, NYU Langone Health, New \\ York, NY 10016, USA. Email: tksusheel.kumar@nyulangone.org.
}

\begin{abstract}
Congenitally corrected transposition of the great arteries (CCTGA) is a rare congenital heart lesion with varied morphological presentation and can often by asymptomatic. A failing systemic right ventricle (RV) or increasing tricuspid regurgitation are generally indications for surgical intervention. The surgical approach depends upon the age of the patient and morphology of the lesion. Anatomical correction is associated with satisfactory long-term results.
\end{abstract}

Keywords: Congenital; transposition; operation

Submitted Sep 17, 2019. Accepted for publication Oct 29, 2019.

doi: $10.21037 /$ jtd.2019.10.15

View this article at: http://dx.doi.org/10.21037/jtd.2019.10.15

Congenitally corrected transposition of the great arteries (CCTGA) is a rare structural heart disease constituting less than $1 \%$ of all congenital heart disease (1). It is a unique congenital heart lesion in the sense that despite anatomical aberrations in the form of atrioventricular and ventriculoarterial discordance, there can be physiologically normal circulation without any mixing or shunting of blood. While the indications and techniques for surgical correction of CCTGA continue to evolve, this review seeks to shed light on the rationale and broad principles of surgical intervention that are in vogue today.

\section{Anatomy}

It is critical to appreciate the anatomical variations that CCTGA can present with to plan surgical intervention. In its simplest form, CCTGA presents as an isolated combination of atrioventricular and ventriculoarterial discordance without any other structural abnormalities in SLL configuration (Figure 1) (2). In this form, the atria are in normal position with the left ventricle (LV) on the right side. The great vessels are L-malposed with the aorta anterior and to the left of the main pulmonary artery. The interventricular septum lies in a straight anteroposterior plane with side by side ventricles. The conduction pathway is abnormal with the atrioventricular node lying anteriorly at the junction of the right sided mitral valve annulus and the limbus of the septum secundum (3). The atrioventricular

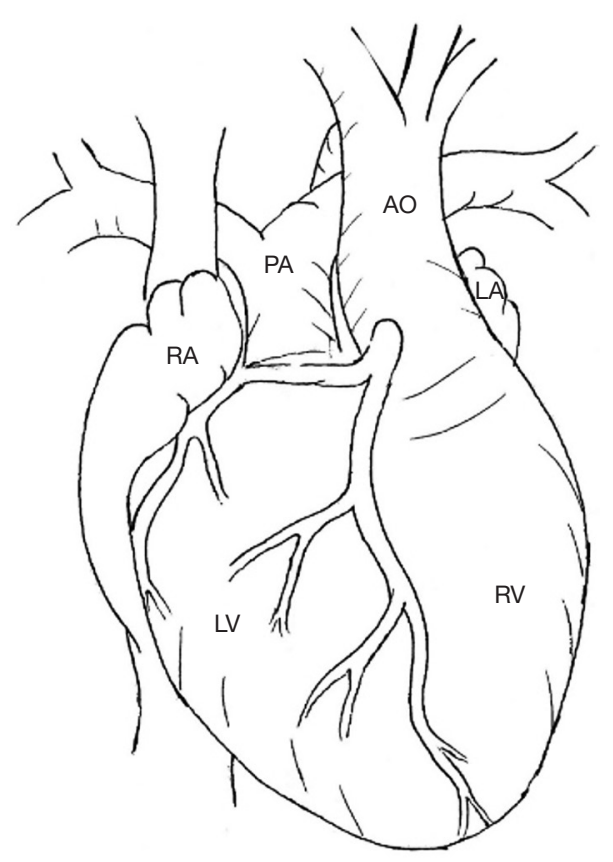

Figure 1 showing the typical anatomy of congenitally corrected transposition of the great arteries. The right sided coronary artery crosses the left ventricular outflow tract. The left sided coronary artery arises from the left facing sinus and is not shown here as it courses behind the aorta to reach the left sided morphological right ventricle. RA, right atrium; LA, left atrium; RV, right ventricle; $L V$, left ventricle; $\mathrm{PA}$, pulmonary artery; $\mathrm{AO}$, aorta. 


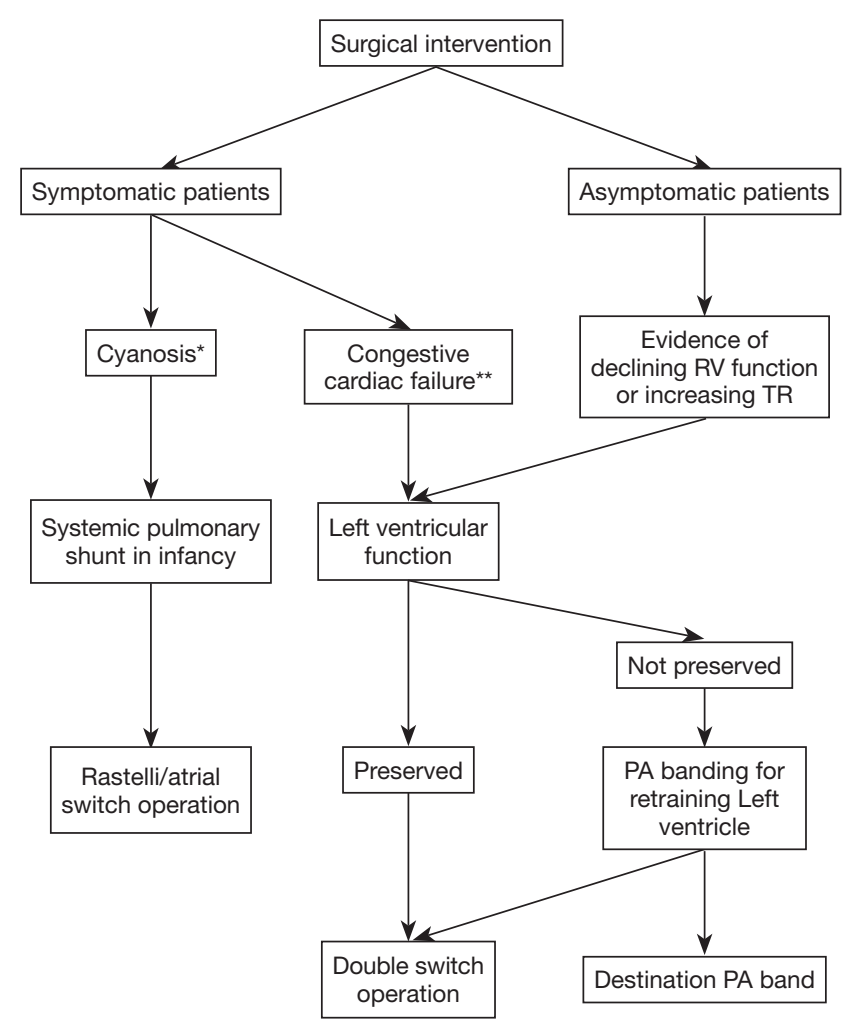

* CCTGA with VSD and LVOTO commonly present with cyanosis ** CCTGA without PS commonly present with heart failure

Figure 2 Indications for surgical intervention in CCTGA. CCTGA, congenitally corrected transposition of the great arteries. $\mathrm{RV}$, right ventricle; $\mathrm{PA}$, pulmonary artery.

bundle then traverses the anterior wall of the morphological LV outflow tract just caudal to the pulmonary valve annulus. It then dives into the interventricular septum lying subendocardially on the right side of the septum (i.e., morphological LV). The bundle thus lies in relation to the anterosuperior border of the ventricular septal defect (VSD) when present. In approximately $70 \%$ to $80 \%$ of the patients there is a conotruncal type of VSD with some malalignment and occasional inlet extension. In the presence of a large VSD, the pulmonary artery may override the VSD and arise largely from the right ventricle (RV) resulting in double outlet RV. Left ventricular outflow tract obstruction (LVOTO) occurs in about $25 \%$ to $50 \%$ of the cases with or without a VSD and can occur at the level of pulmonary valve or below the valve. So most patients of CCTGA have a VSD with pulmonary stenosis. The left atrioventricular valve sometimes shows Ebstenoid features and regurgitation in approximately one-third of the cases.
In situs inversus (10\% of the cases) CCTGA can present in IDD configuration. In these cases, the conduction pathway resembles a normal tract with the atrioventricular node lying posteriorly (4). Levocardia usually exists with situs solitus but dextrocardia can complicate the anatomical presentation in approximately $25 \%$ of the cases adding an additional layer of complexity to the surgical operation (2).

\section{Clinical features and diagnosis}

Many patients with CCTGA are asymptomatic and diagnosed during routine cardiac evaluation on chest X-ray or ECG. Common presenting symptoms are cyanosis and dyspnea. These are a result of failing RV or tricuspid valve functioning at systemic pressure or associated anomalies such as LVOTO and VSD. Chest X-ray is abnormal because of dextrocardia or abnormal cardiac silhouette as a result of L posed aorta. ECG demonstrates superior QRS axis with atypical septal activation as shown by absence of $\mathrm{q}$ waves in left precordial leads. Echocardiogram is diagnostic and demonstrates the associated features well. Cardiac MRI is useful to study complex LVOTO and feasibility of baffling difficult VSD. Cardiac catheterization is needed to assess pulmonary vascular resistance in the older patients without any LVOTO (1).

\section{Indications for surgical intervention}

Generally surgical intervention is reserved for symptomatic patients and asymptomatic patients with evidence of declining $\mathrm{RV}$ function and worsening tricuspid regurgitation (Figure 2). Intervention on asymptomatic patients with preserved $\mathrm{RV}$ function and tricuspid valve function without any other septal defects is controversial considering that some patients with CCTGA tend to have a favorable prognosis and surgical intervention is associated with risks and long-term issues (5).

\section{Surgical strategies and outcomes}

Traditional or classic or physiologic operation of CCTGA involves correction of the septal defects or LVOTO or left atrioventricular valve regurgitation without correction of atrioventricular and ventriculoarterial discordance. Although the shunting and obstruction to flow of blood is eliminated, the RV and the tricuspid valve continue to function at systemic pressures. The VSD is closed via the mitral valve with suture placement on the RV side of the septum as described by Dr. de Leval (6). An alternate approach to closure of VSD in the older patient is across 


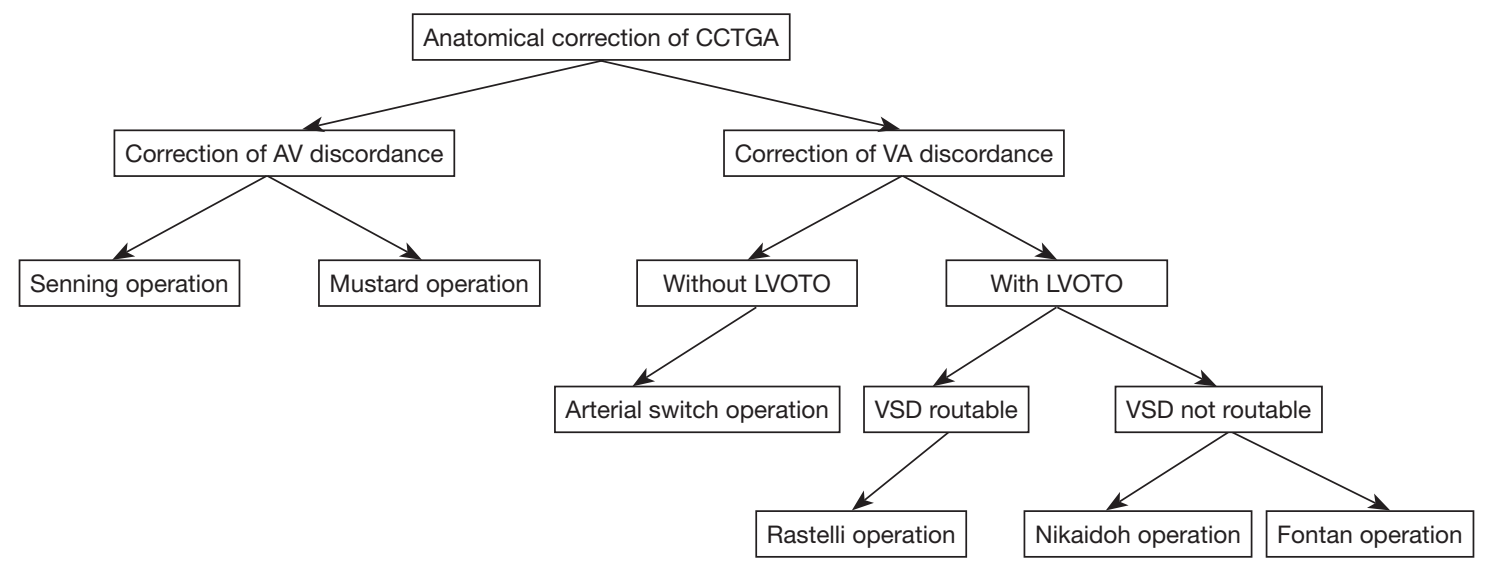

Figure 3 Algorithm for anatomical correction of CCTGA. CCTGA, congenitally corrected transposition of the great arteries; LVOTO, left ventricular outflow tract obstruction; VSD, ventricular septal defect.

the aortic valve. Although one can avoid the conduction pathway the aortic valve is at risk with this approach (2). A LV to pulmonary artery conduit is generally used for relief of pulmonary outflow tract obstruction often resulting in double outlet LV. The transannular patch is not a good option as the right sided coronary artery crosses the left ventricular outflow tract. In addition, there is the risk of complete heart block as the conduction pathway crosses the left ventricular outflow tract. The incision on the LV must be placed carefully to avoid injury to the anterior papillary muscle of the mitral valve. The incision must also be placed well below the pulmonary valve to avoid the conduction pathway (2). An undersized conduit is preferable as pulmonary stenosis is known to impart protection against RV failure (5). Because longer conduits are often required, composite conduits consisting of pulmonary homografts attached to synthetic tube extensions have been described (2). Repair or replacement of the leaking left atrioventricular valve have not been associated with encouraging long-term results (7). The results of the physiologic approach are thus poor overall and various studies have reported continued attrition of patients following traditional surgical management because of declining RV function or increase in systemic atrioventricular valve regurgitation (8-11). Despite these limitations, the physiologic approach may be useful in certain settings such as older patients with well-preserved RV and tricuspid valve who may be high risk candidates for anatomic repair (12).

Anatomic operation for CCTGA first described by Ilbawi and colleagues involves correction of atrioventricular and ventriculoarterial discordance in the form of double switch operation (Figure 3) (10). The term double switch operation is generally refers to the combination of atrial switch procedure (either Senning or Mustard operation) with either arterial switch operation or Rastelli operation while some authors use it strictly to refer to the combination of arterial with atrial switch procedure. The anatomic operation was propelled by disappointing longterm results with the physiologic approach. A pre-requisite for anatomical correction of CCTGA is a conditioned LV. The LV remains naturally conditioned in presence of a large VSD or significant LVOTO making an anatomical correction feasible at any point. The question of $\mathrm{LV}$ adequacy to support the systemic circulation arises in the setting of intact ventricular septum or absence of LVOTO. In such cases pulmonary artery banding to retrain the $\mathrm{LV}$ may be required (13). Various criteria for adequacy of $\mathrm{LV}$ such as LV free wall thickness compared to age matched controls and LV mass have been described $(13,14)$. Novel techniques to create percutaneous adjustable pulmonary artery band have been described (15). It is generally accepted that $\mathrm{LV}$ retraining produces good results in the younger patients and is associated with higher mortality in the older patients (16). In addition, there are reports that suggest that patients who require preliminary $L V$ training before the double switch operation do not do as well in the long-term as those who do not (17). Pulmonary artery band is also an effective palliative procedure ('destination band') in the older patients who cannot undergo $\mathrm{LV}$ training (16).

Techniques for correction of atrioventricular discordance include the Senning and Mustard operations. The Senning operation is a common form of atrial switch procedure. In this procedure the right atrial wall is designed to form the roof of the systemic venous pathway while the atrial septal flap (often augmented with native pericardium or synthetic 
material) is sutured to the posterior wall of the left atrium to form the roof of the pulmonary venous pathway. By rotating the flaps created from the right atrial wall and the septum the systemic venous blood is diverted to the left sided RV. The anterior wall of the pulmonary venous pathway is completed by suturing the free edge of the right atriotomy to the posterior edge of the left atriotomy. This anastomosis is often augmented using in situ native pericardium ('Modified Senning') $(18,19)$. The Mustard operation achieves the same by using a single pantaloon shaped patch (18). It is especially useful when the right atrium is small as in dextrocardia, juxtaposition of the right atrial appendage or apicocaval juxtaposition. Using a single continuous suture, the patch is sewn around the orifices of the superior and inferior venae cavae and to the posterior wall of the left atrium above the left pulmonary veins to divert the deoxygenated blood to the left sided RV (18). A more recent modification of the atrial switch procedure is the Hemi-Mustard operation popularized by Dr. Hanley wherein only the venous return from the inferior vena cava is diverted to the left sided $\mathrm{RV}$ while the superior vena cava is connected directly to the right pulmonary artery as Glenn operation effectively resulting in one and half ventricle repair (20).

Correction of ventriculoarterial discordance depends on the presence of LVOTO and location of VSD (Figure 3). When LVOTO is in the form of pulmonary valve stenosis and arterial switch operation is not an option, one should consider the Rastelli procedure. Dynamic or mild fixed LVOTO does not rule out arterial switch procedure. The arterial switch operation is done in presence of good sized main pulmonary artery annulus. However, it is important to rule out increased pulmonary vascular resistance in older patients without restriction of pulmonary blood flow. A subaortic conus is present as in D-TGA. Hence the steps are essentially the same as in a standard arterial switch procedure $(14,18,19)$. The Lecompte maneuver can be done in the usual manner. The VSD is closed either through the neopulmonary valve after the coronaries have been harvested or the right atrium. The coronary anatomy can vary from that generally seen in D-TGA. The coronary ostia are generally located deeper in the aortic sinuses and the coronary arteries tend to bifurcate early making rotation of the coronary buttons difficult and sometimes necessitating pericardial patch augmentation to avoid kinking of the coronaries $(14,18,19)$. Elective repair of CCTGA with a large VSD in the form of a double switch operation can be done at 6 months of age (19).

The Rastelli operation is a form of ventricular switch procedure that can be used in situations with fixed LVOTO and favorable location of VSD that allow routing of morphological LV into aorta (Figure 3). The decision regarding feasibility of VSD closure is made through right atrial incision rather than ventriculotomy as the bailout operation is Fontan if the VSD is not routable. Once feasibility is confirmed, a vertical incision is placed over the mid portion of the RV to avoid coronaries (18). The proximal main pulmonary artery is divided, pulmonary valve excised and pulmonary artery stump over sewn. The VSD is closed via the incision over the RV. Either pericardium (native or treated) or a synthetic patch can be used to baffle the VSD to the aorta using a continuous or interrupted suture line. The suture line thus lies entirely on the RV side of the septum. Rarely enlargement of the VSD may be required in the posteroinferior region. When subaortic area is a concern or VSD is restrictive and needs enlargement, the DKS procedure may be used as an alternative procedure thus creating a double outlet LV (21). The DKS procedure is effective in avoiding systemic outflow tract obstruction as well as surgical heart block (21). The RV to pulmonary artery conduit lies either to the right or left of the ascending aorta away from the sternum $(2,18)$. Consideration should be given to placement of permanent pacing electrodes after any surgical intervention on CCTGA because of the high risk of complete heart block. Dextrocardia makes the Senning component of the operation challenging and complicates the lie of the RV to pulmonary conduit in Rastelli operation $(2,18)$. The modified Nikaidoh aortic root translocation procedure has been utilized for patients with CCTGA, VSD and LVOTO when the VSD has not been suitable for a Rastelli operation $(22,23)$. However, the experience is still limited and the Nikaidoh procedure has some limitations. The overall experience with the double switch and atrial switch/ Rastelli operation has been satisfactory with preservation of $\mathrm{LV}$ function and decrease in left atrioventricular valve regurgitation. Heart block, superior vena caval pathway obstruction and conduit stenosis requiring replacement are the most commonly reported complications (14,24-26).

The one and half approach as advocated by Dr. Hanley et al is especially useful in RV hypoplasia although some authors have described the use of fenestration of the atrial septal defect patch to offload the RV $(14,20)$. The group has described the hemi-Mustard procedure to baffle the inferior caval return to the tricuspid valve in conjunction with a bidirectional Glenn operation for the atrial switch component of the double switch operation or the Rastelli/atrial switch operation. Advantages of this approach include the lesser incidence of sinus node dysfunction, systemic venous baffle 
obstruction, tricuspid valve regurgitation and reintervention on the RV to pulmonary artery conduit as a result of reduced volume load on the RV (20). The approach is also useful in patients with dextrocardia where the small right atrium may not be suitable for a traditional Senning operation.

The Fontan operation is used in situation of CCTGA with VSD and LVOTO when Rastelli is not possible because of unfavorable anatomy as a result of dextrocardia, multiple or remote VSD, coronary anomalies, straddling atrioventricular valves or ventricular hypoplasia (12). Historically most patients with CCTGA who have undergone Fontan procedure have been deemed unsuitable for anatomic repair based on difficult anatomic criteria and there are no good studies that have documented long term outcome of such patients (27). Since attrition of patients undergoing Fontan procedure is well documented, most institutions favor the anatomic repair for patients with CCTGA and favorable anatomic features. Tricuspid insufficiency could however limit application of the Fontan operation as the valve is still subjected to systemic pressures (28). The Fontan procedure however has better outcomes in comparison to the physiologic operation for CCTGA (9).

Finally, heart transplantation may be the only option for certain patients with CCTGA who are either too old for LV retraining and anatomic repair or have bad outcomes following anatomic or Fontan repair. Technical modifications are necessary to achieve good outcomes (29).

\section{Conclusions}

CCTGA is indeed a complex congenital heart disease. Surgical management of CCTGA has evolved from physiologic repair that addressed only the associated structural defects to an anatomic repair that establishes the morphological LV as the systemic ventricle. Although the outcomes with the anatomic repair are better, multi institutional studies are required to refine the indications for surgical intervention especially in absence of associated structural defects. Uniform criteria for adequacy of $\mathrm{LV}$ to support systemic circulation following retraining need to be defined. The place of destination pulmonary artery bands in older patients and Fontan operation in high risk anatomic repair need further experience and studies as do the indications for heart transplantation.

\section{Acknowledgments}

Funding: None.

\section{Footnote}

Provenance and Peer Review: This article was commissioned by the Guest Editor (Raghav A. Murthy) for the series "Management of Congenital Heart Disease" published in Fournal of Thoracic Disease. The article was sent for external peer review organized by the Guest Editor and the editorial office.

Conflicts of Interest: The series "Management of Congenital Heart Disease" was commissioned by the editorial office without any funding or sponsorship. The author has no other conflicts of interest to declare.

Ethical Statement: The author is accountable for all aspects of the work in ensuring that questions related to the accuracy or integrity of any part of the work are appropriately investigated and resolved.

Open Access Statement: This is an Open Access article distributed in accordance with the Creative Commons Attribution-NonCommercial-NoDerivs 4.0 International License (CC BY-NC-ND 4.0), which permits the noncommercial replication and distribution of the article with the strict proviso that no changes or edits are made and the original work is properly cited (including links to both the formal publication through the relevant DOI and the license). See: https://creativecommons.org/licenses/by-nc-nd/4.0/.

\section{References}

1. Jonas RA. Comprehensive Surgical Management of Congenital Heart Disease. Second editon Boca Raton, Florida: CRC Press, 2014.

2. Bove EL. Congenitally corrected transposition of the great arteries: ventricle to pulmonary artery connection strategies. Semin Thorac Cardiovasc Surg 1995;7:139-44.

3. Anderson RH, Becker AE, Arnold R, et al. The conducting tissues in congenitally corrected transposition. Circulation 1974;50:911-23.

4. Wilkinson JL, Smith A, Lincoln C, et al. Conducting tissues in congenitally corrected transposition with situs inversus. Br Heart J 1978;40:41-8.

5. Helsen F, De Meester P, Van Keer J, et al. Pulmonary outflow obstruction protects against heart failure in adults with congenitally corrected transposition of the great arteries. Int J Cardiol 2015;196:1-6.

6. de Leval MR, Bastos P, Stark J. Surgical technique to reduce the risks of heart block following closure of 
ventricular septal defect in atrioventricular discordance. J Thorac Cardiovasc Surg 1979;78:515-26.

7. van Son JA, Danielson GK, Huhta JC, et al. Late results of systemic atrioventricular valve replacement in corrected transposition. J Thorac Cardiovasc Surg 1995;109:642-52; discussion 652-3.

8. Sano T, Riesenfeld T, Karl TR, et al. Intermediateterm outcome after intracardiac repair of associated cardiac defects in patients with atrioventricular and ventriculoarterial discordance. Circulation 1995;92:II272-8.

9. Hraska V, Duncan BW, Mayer JE, et al. Long-term outcome of surgically treated patients with corrected transposition of the great arteries. J Thorac Cardiovasc Surg 2005;129:182-91.

10. Ilbawi MN, DeLeon SY, Backer CL, et al. An alternative approach to the surgical management of physiologically corrected transposition with ventricular septal defect and pulmonary stenosis or atresia. J Thorac Cardiovasc Surg 1990;100:410-5.

11. McGrath LB, Kirklin JW, Blackstone EH, et al. Death and other events after cardiac repair in discordant atrioventricular connection. J Thorac Cardiovasc Surg 1985;90:711-28.

12. Karl TR. The role of the Fontan operation in the treatment of congenitally corrected transposition of the great arteries. Ann Pediatr Cardiol 2011;4:103-10.

13. Ibrahimiye AN, Mainwaring RD, Patrick WL, et al. Left Ventricular Retraining and Double Switch in Patients With Congenitally Corrected Transposition of the Great Arteries. World J Pediatr Congenit Heart Surg 2017;8:203-9.

14. Sharma R, Bhan A, Juneja R, et al. Double switch for congenitally corrected transposition of the great arteries. Eur J Cardiothorac Surg 1999;15:276-81; discussion 81-2.

15. Dibardino DJ, Kleeman K, Bove EL. A method of transcutaneously adjustable pulmonary artery banding for staged left ventricular retraining. J Thorac Cardiovasc Surg 2012;144:553-6.

16. Winlaw DS, McGuirk SP, Balmer C, et al. Intention-totreat analysis of pulmonary artery banding in conditions with a morphological right ventricle in the systemic circulation with a view to anatomic biventricular repair. Circulation 2005;111:405-11.

17. Brawn WJ, Barron DJ, Jones TJ, et al. The fate of the retrained left ventricle after double switch procedure for congenitally corrected transposition of the great arteries. Semin Thorac Cardiovasc Surg Pediatr Card Surg Annu 2008:69-73.

18. Reddy VM, McElhinney DB, Silverman NH, et al. The double switch procedure for anatomical repair of congenitally corrected transposition of the great arteries in infants and children. Eur Heart J 1997;18:1470-7.
19. Devaney EJ, Ohye RG, Bove EL. Technical aspects of the combined arterial switch and senning operation for congenitally corrected transposition of the great arteries. Semin Thorac Cardiovasc Surg Pediatr Card Surg Annu 2003;6:9-15.

20. Malhotra SP, Reddy VM, Qiu M, et al. The hemiMustard/bidirectional Glenn atrial switch procedure in the double-switch operation for congenitally corrected transposition of the great arteries: rationale and midterm results. J Thorac Cardiovasc Surg 2011;141:162-70.

21. Hoashi T, Kagisaki K, Miyazaki A, et al. Anatomic repair for corrected transposition with left ventricular outflow tract obstruction. Ann Thorac Surg 2013;96:611-20.

22. Davies B, Oppido G, Wilkinson JL, et al. Aortic translocation, Senning procedure and right ventricular outflow tract augmentation for congenitally corrected transposition, ventricular septal defect and pulmonary stenosis. Eur J Cardiothorac Surg 2008;33:934-6.

23. Kwak JG, Lee CH, Lee C, et al. Aortic root translocation with atrial switch: another surgical option for congenitally corrected transposition of the great arteries with isolated pulmonary stenosis. J Thorac Cardiovasc Surg 2010;139:1652-3.

24. Hiramatsu T, Matsumura G, Konuma T, et al. Long-term prognosis of double-switch operation for congenitally corrected transposition of the great arteries. Eur J Cardiothorac Surg 2012;42:1004-8.

25. Gaies MG, Goldberg CS, Ohye RG, et al. Early and intermediate outcome after anatomic repair of congenitally corrected transposition of the great arteries. Ann Thorac Surg 2009;88:1952-60.

26. Murtuza B, Barron DJ, Stumper O, et al. Anatomic repair for congenitally corrected transposition of the great arteries: a single-institution 19-year experience. J Thorac Cardiovasc Surg 2011;142:1348-57.e1.

27. Shin'oka T, Kurosawa H, Imai Y, et al. Outcomes of definitive surgical repair for congenitally corrected transposition of the great arteries or double outlet right ventricle with discordant atrioventricular connections: risk analyses in 189 patients. J Thorac Cardiovasc Surg 2007;133:1318-28, 1328.e1-4.

28. Hörer J, Schreiber C, Krane S, et al. Outcome after surgical repair/palliation of congenitally corrected transposition of the great arteries. Thorac Cardiovasc Surg 2008;56:391-7.

29. Sue SH, Wei J, Chuang YC, et al. Cardiac transplantation for congenitally corrected transposition of the great arteries: a case report. Transplant Proc 2008;40:2844-5.

Cite this article as: Kumar TKS. Congenitally corrected transposition of the great arteries. J Thorac Dis 2020;12(3):1213-1218. doi: 10.21037/jtd.2019.10.15 